\title{
Sustentabilidade é um modo de ser da ética
}

\section{Sustainability is an ethical way of being}

DOI: $10.46814 /$ lajdv2n6-019

Recebimento dos originais: 01/09/2020

Aceitação para publicação: 30/10/2020

\section{Vanessa Steigleder Neubauer}

Doutora em Filosofia pela UNISINOS, Docente da Universidade de Cruz Alta.

E-mail: vneubauer@unicruz.edu.br

Ieda Márcia Donati Linck

Docente da Universidade de Cruz Alta (Unicruz). Doutora em Linguística pela UFSM e UA/Portugal.

E-mail: imdlinck@gmail.com

\section{Isadora Wayhs Cadore Virgolin}

Docente Unicruz, Doutora em Extensão Rural pela Universidade Federal de Santa Maria - UFSM.

E-mail: ivirgolin@unicruz.edu.br

\section{Rafael Vieira de Mello Lopes}

Doutorando em Direito URI Santo Ângelo, Mestre em Educação nas Ciências, Universidade Regional do Noroeste do Estado do Rio Grande do Sul. Especialista em Direito Civil e Processual

Civil pela Universidade de Cruz Alta - UNICRUZ. Especialista em Formação Pedagógica pela Universidade do Estado do Rio Grande do Sul - UERGS. Integrante do Grupo de Pesquisa Jurídica em Cidadania, Democracia e Direitos Humanos - GPJUR - UNICRUZ. Professor do Curso de Direito

- UNICRUZ. Advogado.

E-mail: ralopes@unicruz.edu.br

\section{Ângela Simone Keitel}

Mestra em Direito pela URI - Universidade Regional Integrada do Alto Uruguai e das Missões. Graduada em Ciências Jurídicas pela UNICRUZ - Universidade de Cruz Alta. Professora titular da Universidade de Cruz Alta. Coordenadora do Núcleo de Ação Pró-Direitos Humanos. Integrante do Grupo de Pesquisa Jurídica em Cidadania, Democracia e Direitos Humanos - GPJUR - UNICRUZ.

E-mail: angelakeitel@unicruz.edu.br

\section{RESUMO}

O presente texto vem ponderar sobre a comunicação persuasiva. A regra universal da ética da comunicação baseia-se no acordo acerca dos princípios de informação e de argumentação. $\mathrm{O}$ cumprimento da regra mencionada permite a explicação de situações de conflito, assim como o esclarecimento das mensagens ilegíveis. Os meios de comunicação social alcançaram tamanha importância que são para muitos o principal instrumento de informação e formação, de guia e inspiração de comportamentos individuais e coletivos.

A responsabilidade da informação quanto ao exercício da verdade explica a importância da ética na comunicação. Existe um princípio que afirma que "todo indivíduo tem direito à informação e direito de informar". O direito à informação fundamenta-se não só na dignidade do indivíduo, mas também 
na exigência do bem comum; o direito de informar está na base da liberdade de expressão. Não podemos esquecer que os interesses econômicos, políticos, artísticos e de audiência nunca podem ser colocados acima da lei moral ou do bem comum.

No entanto, para que isso seja levado a efeito, Gomes (1997) afirma que o debate sobre a ética da comunicação movimenta-se em dois parâmetros. Por um lado, deve-se denunciar tudo aquilo que significa desmoralização, abuso e negação de valores universais. Por outro, deve-se identificar os sinais da evolução, buscando novas perspectivas e novos valores para o trabalho diário. A partir desse debate podemos compreender a importância da ética para atuar como um profissional de comunicação.

Palavras-Chaves: Respeito, Responsabilidade, Informação.

\begin{abstract}
This text considers the persuasive communication. The universal rule of communication ethics is based on agreement on the principles of information and reasoning. Compliance with the mentioned rule allows the explanation of conflict situations, as well as the clarification of unreadable messages. The media has reached such importance that they are for many the main instrument of information and training, of guiding and inspiring individual and collective behaviors.

The responsibility for information regarding the exercise of truth explains the importance of ethics in communication. There is a principle that states that "everyone has the right to information and the right to inform". The right to information is based not only on the dignity of the individual, but also on the demand for the common good; the right to inform is at the basis of freedom of expression. We must not forget that economic, political, artistic and audience interests can never be placed above moral law or the common good.

However, for this to be carried out, Gomes (1997) states that the debate on the ethics of communication moves in two parameters. On the one hand, everything that means demoralization, abuse and denial of universal values must be denounced. On the other hand, signs of evolution must be identified, seeking new perspectives and new values for daily work. From this debate we can understand the importance of ethics to act as a communication professional.
\end{abstract}

Keywords: Respect, Responsibility, Information.

\title{
1 INTRODUÇÃO
}

A facilidade de acesso à informação e o aumento considerável dos canais informativos criaram certos perigos. Em consequência, a liberdade de comunicação aumenta a responsabilidade individual nas mensagens e nos seus efeitos. O problema é particularmente visível no caso da comunicação persuasiva, como, por exemplo, a publicidade ou propaganda onde a fronteira entre manipulação e informação tende a ser frágil, bem como no jornalismo onde interesses econômicos ou políticos, às vezes, prevalecem em detrimento da imparcialidade, transparência, veracidade e seriedade das informações divulgadas.

A regra universal da ética da comunicação baseia-se no acordo acerca dos princípios de informação e de argumentação. O cumprimento da regra mencionada permite a explicação de situações de conflito, assim como o esclarecimento das mensagens ilegíveis. Há algum tempo, “O 
povo" publicou uma reportagem intitulada "Papa critica meios de comunicação" (cf. p. 32). Segundo o jornal, "o Papa Bento XVI atacou duramente os meios de comunicação por impor modelos distorcidos, empregar publicidade obsessiva e recorrer à transgressão, vulgaridade e violência para atrair o público, além de convidar os profissionais da área a desenvolver uma informação ética".

As críticas, bem como as palavras do referido Papa exigem uma reflexão. O primeiro retrato dos tempos modernos é o mundo das comunicações, que está unificando a humanidade, transformando-a na aldeia global. Os meios de comunicação social alcançaram tamanha importância que são para muitos o principal instrumento de informação e formação, de guia e inspiração de comportamentos individuais e coletivos.

A responsabilidade da informação quanto ao exercício da verdade explica a importância da ética na comunicação. Existe um princípio que afirma que "todo indivíduo tem direito à informação e direito de informar". O direito à informação fundamenta-se não só na dignidade do indivíduo, mas também na exigência do bem comum; o direito de informar está na base da liberdade de expressão. Não podemos esquecer que os interesses econômicos, políticos, artísticos e de audiência nunca podem ser colocados acima da lei moral ou do bem comum.

No entanto, para que isso seja levado a efeito, Gomes (1997) afirma que o debate sobre a ética da comunicação movimenta-se em dois parâmetros. Por um lado, deve-se denunciar tudo aquilo que significa desmoralização, abuso e negação de valores universais. Por outro, deve-se identificar os sinais da evolução, buscando novas perspectivas e novos valores para o trabalho diário. A partir desse debate podemos compreender a importância da ética para atuar como um profissional de comunicação.

\section{VALE PENSAR: O QUE É ÉTICA?}

A palavra "ética" provém do grego "ethos" e significa o caráter cultural e social de uma sociedade. Designa o modo de ser, o espírito de uma época ou de um povo, cujo sentido está fortemente vinculado à expressão "moral", que vem do latim "morale" e se refere a costume. No cerne da questão, ética se refere ao discernimento entre o que é tido como certo ou errado, bem ou mal em uma certa época e em dada sociedade. É a ciência que analisa os atos humanos e que tem como objeto a moral.

Segundo o Dicionário Larrouse (2000), ética é "o estudo dos juízos de apreciação que se referem à conduta humana susceptível de qualificação do ponto de vista do bem e do mal, seja relativamente à determinada sociedade, seja de modo absoluto". 
A ética trata dos valores morais de um cidadão, que é, frequentemente, exposto à corrupção política, ao sensacionalismo produzido por determinados meios de comunicação, sem importar-se com os efeitos causados no público. A busca de um fazer ético é constante em todos os âmbitos, seja na economia, na educação, na política ou na comunicação o interesse é de todos. Desta tão unânime almejada ética, Weil (1994) afirma:

Muitos são os que paralelamente, a infringem, se comportando de modo inadequado, mesmo sabendo que estão indo contra certos valores essenciais. Isto nos mostra que pelo menos esta forma de ética não é suficientemente forte e carece de poder para levar as pessoas a um comportamento ético verdadeiramente autêntico (WEIL, 1994, p. 61).

Definir o que é um agir ético, correto ou virtuoso é se inscrever numa disputa social pela definição legítima de boa conduta; da conduta verdadeira e necessária. Uma ética baseada na consciência individual tem insuficiência muito semelhante àquelas de uma ética baseada nos códigos, mas o que é ético e moral para um, pode não ser para o outro. Justamente porque todos sustentam serem alguns códigos éticos e morais melhores que os outros. Assim como Russell comenta em seu livro "A sociedade humana na ética e na política":

As consciências individuais diferem: impugnadores cocientes consideram errado lutar; assassinos consideram errado abster-se da luta; os Maniqueus julgavam nocivo comer qualquer alimento animal, exceto peixe, mas certas seitas têm considerado esta exceção como abominável. Os Dukhobors se recusavam a prestar serviço militar, mas achavam natural dançarem nus, todos juntos em volta de uma fogueira (RUSSELL, 1956, s/p).

A confusão que acontece entre as palavras moral e ética existe há muito tempo. A moral sempre existiu, pois todo ser humano possui a consciência moral; no entanto, a ética teria surgido com Sócrates, pois se exige maior grau de cultura. Ela investiga e explica as normas morais, pois leva o homem a agir não só por tradição, educação ou hábito, mas principalmente por convicção e inteligência.

A ética também não deve ser confundida com a lei embora, com certa frequência, a lei tenha como base princípios éticos. Ao contrário do que ocorre com a lei, nenhum indivíduo pode ser compelido, pelo Estado ou por outros indivíduos, a cumprir as normas éticas, nem sofrer qualquer sanção pela desobediência a estas; por outro lado, a lei pode ser omissa quanto a questões abrangidas se referirem ao escopo da ética.

Ética e moral são os maiores valores do homem livre. Ambos significam "respeitar e venerar a vida". O homem, com seu livre arbítrio, vai formando ou destruindo seu meio ambiente, ou ele apoia a natureza e suas criaturas ou ele subjuga tudo que pode dominar, e assim ele mesmo se torna com 
base no bem ou no mal deste planeta. Desse modo, a ética e a moral se formam numa mesma realidade. No entanto, no entendimento de Sá (2001, p. 26):

A ética é um estado de espírito é quase hereditário e vem da formação e do meio social do qual a criança teve sua personalidade moldada, para ingressar no convívio da sociedade, que é o que popularmente denomina-se berço, e moral é adquirida por meio da educação formal e da experiência da vida.

Vale pensar, então, o quanto a educação familiar, escolar e social interfere na formação do caráter e da personalidade de um cidadão que, na maioria das vezes têm, também, nas programações dos meios de comunicação um recurso para adquirir conhecimentos e experiências de vida, que são constitutivos.

\section{A PRÁTICA PROFISSIONAL, ALÉM OU AQUÉM DA ÉTICA...}

Ética profissional é o conjunto de regras morais de comportamento que todos devem observar em suas profissões para melhor servir colegas, chefes, sócios, parceiros, colaboradores e clientes e para que suas atividades venham atingir a qualidade desejada. Corresponde a parte da ética aplicada (ética ecológica, ética a e familiar...), debruçando-se sobre um conjunto de atividades humanamente engajadas e socialmente produtivas. Vincula-se à ideia de utilidade, prestabilidade, lucratividade, categoria laboral, engajamento em modos de produção ou prestação de serviço, exercício de atividades regularmente desenvolvidas de acordo com finalidades sociais.

Em sua essência a ética profissional trata da aplicação dos princípios morais aceitos como certos para sociedade, tendo como referência a ética geral. É ela que garante uma carreira longa e eficaz.

\footnotetext{
A pessoa tem que estar imbuída de certos princípios ou valores próprios do ser humano para vivenciá-lo nas suas atividades de trabalho. De um ou lado, ela exige a deontologia, isto é, o estudo dos deveres específicos que orientam o agir humano no seu campo profissional; de outro lado, exige a diciologia, isto é, o estudo dos direitos que a pessoa tem ao exercer suas atividades (CAMARGO, 1999, p. 33).
}

O exercício profissional deve ser sempre realizado com vistas à proteção da dignidade humana. "O que é natural, como ético, é que a profissão esteja a serviço do social, quer das células, quer do conjunto indiscriminadamente" (SÁ, 2009, p.156). Assim, o profissional que atua na área de comunicação precisa agir com comprometimento, responsabilidade e, sobretudo, respeito ao próximo, já que contribui para formar imaginários, instituir prioridades, definir e rejeitar escolhas, enfim influenciar os modos de ser, agir e pensar de uma sociedade. 
Atualmente, o valor de uma informação que percorre o mundo inteiro através das evoluções tecnológicas, empregadas pelos diversos veículos de comunicação, depende de uma estrutura ética que cada um destes meios determina. Uma notícia jornalística inadequada, na qual a verdade não predomina, compromete a imagem, bem como toda a estrutura de uma empresa de comunicação.

No jornalismo, a ética é mais que rótulo, que acessório. No exercício cotidiano da cobertura dos fatos que interessam à sociedade, a conduta ética se mistura com a própria qualidade técnica de produção do trabalho. Repórteres, redatores e editores precisam dominar equipamentos e linguagens, mas não devem se descolar de seus comprometimentos e valores (CHRISTO FOLETTI, 2008, p.11).

Nos meios de comunicação sejam eles privados ou públicos, os jornalistas deve(ria)m estar a serviço da coletividade e não de um grupo específico. Um produto midiático tem a possibilidade de intervir nos valores e na formação, principalmente das crianças e adolescentes. É preciso saber que cada opção/pauta acarreta em consequências e, por sua vez, cada decisão/reportagem provoca responsabilidades cujos efeitos podem ser positivos e negativos. Por isso, a ética nunca pode ser esquecida, pois a informação é destinada a vários públicos, ou seja, àqueles que não têm criticidade suficiente para avaliar a veracidade e seriedade dos conteúdos divulgados e também àqueles que possuem percepção suficiente para procurar informações que venham a contribuir para uma visão de mundo mais humana.

Desse modo, o que define o estatuto ético de uma determinada profissão é a responsabilidade que dela decorre, pois quanto maior sua importância, maior a responsabilidade que dela provém em face dos outros.

\section{A ÉTICA NA PRÁXIS EM ASSESSORIAS MUNICIPAIS}

No interior, geralmente, as prefeituras com suas assessorias de comunicação, quando existem, são responsáveis pelas principais notícias divulgadas em rádios e jornais da respectiva região. Esses veículos de comunicação são patrocinados por algumas empresas privadas, e ali estaria a resposta para os leitores e ouvintes que se perguntam o porquê de tanta ênfase para determinadas notícias sobre obras e eventos municipais, e outras tão importantes nem se quer são divulgadas nesses meios de comunicação.

O trabalho de uma assessoria de comunicação, dentro dos poderes legislativo e executivo, é de suma importância, pois na maioria dos municípios, geralmente os considerados pequenos, não julgam necessário o trabalho especializado de profissionais na área, prejudicando a qualidade da informação que chega até os veículos de comunicação, assim como a credibilidade em expor informações mais relevantes. 
O monopólio é visível em veículos do interior, pois a ética e o interesse pela informação são substituídos pela questão financeira, dando lugar ao grande número de publicidades. Outro motivo que provoca, ou deveria provocar, a indignação de comunidades inteiras é de que certas empresas têm publicidades e informações diárias nas suas publicações, ou seja, aliados políticos que recebem privilégios e aproveitam para lançar suas empresas privadas em campanhas publicitárias.

Em relação aos veículos de comunicação utilizados pelas prefeituras acontecem falhas em que a ética é notavelmente esquecida. Alguns veículos acabam repassando à comunidade somente notícias, pelas quais a prefeitura ou sua assessoria considera o que lhes convêm divulgar. Por estar pagando por aquele espaço, muitas informações em que ocorrem, por exemplo, condenações aos atuais prefeitos, secretários, bem como desavenças e reivindicações internas entre funcionários não são repassadas à comunidade já que não é do interesse da mesma que o público externo fique por dentro de situações internas da casa. Nessa perspectiva:

Deve-se partir do princípio de que a comunicação social é uma das dimensões fundamentais da pessoa. Dependendo como ela é manejada, poderá servir de instrumento de despersonalização. Daí a necessidade de uma proposta ética, que se impõem hoje como tarefa e desafio (BARROS FILHO, 1995, p. 58).

Uma proposta ética deve elaborar e aprofundar a compreensão integral dos objetivos de comunicação, propor e fundar as condições concretas de sua realização no interior das tensões, e mesmo dos conflitos de interesses que existem entre o poder público municipal e os meios/veículos de comunicação.

\section{A VALORIZAÇÃO DA ÉTICA NA COMUNICAÇÃO}

Alguns valores éticos aparecem como deveres na comunicação social em geral e no jornalismo em particular. Esses valores também são chamados de metas e objetivos a atingir e chaves de leituras para sua atuação:

- O ser humano é uma norma no uso dos meios de comunicação social;

- A humanização, por sua vez, é a meta dos meios de comunicação social;

- Exige-se competência e responsabilidade na emissão e na recepção da comunicação;

- Toda comunicação deve estar ajustada á lei fundamental da sinceridade, da verdade;

- Equilíbrio entre formação, informação e recreação;

- A comunicação social é o ambiente próprio para construir uma pessoa humana consciente e critica; 
- Liberdade de comunicação dentro de uma ordem jurídica estabelecida de modo justo. Vale ressaltar:

\begin{abstract}
A história é a própria historia da liberdade, revelando a perfeita identificação de todos os passos da vida humana no planeta como a permanência dos anseios de liberdade, cuja expressão mais profunda e mais pura é a liberdade de pensamento, de que a liberdade de opinião é a maneira de se manifestar (BARROS FILHO, 1995, p. 76).
\end{abstract}

A afirmação da liberdade de expressão parte do sujeito que fala e age na sociedade; o direito à informação parte da sociedade com relação aos sujeitos e instituições. A liberdade de expressão defende que o individuo possui direito a exprimir-se livremente, sem que lhe coloquem travas. A afirmação da liberdade de expressão foi um avanço para o desenvolvimento e o fortalecimento de uma imprensa livre e soberana.

A veracidade e seriedade da informação estão ligadas, de forma direta, aos direitos humanos, à ética e aos princípios que determinam a ação humana na sociedade, com transparência, constância, discernimento e imparcialidade.

Todos podem comunicar os seus pensamentos por palavras, escritas e publicações pela imprensa, sem dependência de censura, contando que hajam de responder pelos abusos que cometerem no exercício deste direito, nos casos e pela forma que a lei determinar (BARROS FILHO, 1995, p. 114).

Nesse percurso, é importante ressaltar que quando se fala em ética e comunicação social, nos deparamos também com vários problemas atuais que desafiam a reflexão ética do pensador/comunicador. Estes problemas são vislumbrados como a correção de erros cometidos e o direito de resposta; o direito de não revelar a fonte da informação, o relacionado com a liberdade de expressão e a responsabilidade informativa, além da privacidade e limites existentes entre a liberdade de pensamentos, de consciência e de informação.

A relação estabelecida se dá porque os valores apresentados são éticos e concerne ao indivíduo como pessoa humana. O ser humano tem seu valor enaltecido porque é digno e capaz de ser governado por valores éticos, apresentando-se aos sujeitos em forma de ideias mestras que não se esgotam. A ética, no contexto midiático, está intimamente ligada às atitudes de questionamento, que vai além de elencar valores e indagar sobre a necessidade deles. Freire (1998, p. 36) evidencia que na promoção do sujeito ingênuo, acrítico para um ser autônomo e crítico, é necessário aproximar-se da "ética e também da estética. Decência e boniteza de mãos dadas". 


\section{A ÉTICA NOS DIFERENTES MEIOS DE COMUNICAÇÃO}

Cada veículo de comunicação tem seu código de ética determinado pelas autoridades, sejam elas nacional, estadual ou municipal de cada área; geralmente os códigos são definidos ou alterados em congressos ou conferências de Jornalismo, de Publicidade e Propaganda, de Relações Públicas, Televisão, Rádio, Jornal ou Web. Os princípios éticos a serem seguidos devem ser os mesmos, seja qual o veículo de informação usado, estes códigos são encontrados na obra Ética e Códigos da Comunicação Social de Alberto André, publicado pela Editora Afiliada em 1994. Muito embora, no exercício da profissão, frequentemente alguns desses princípios são desrespeitados. A ética é infringida no dia a dia das diferentes áreas da comunicação social: da imprensa à publicidade; das relações públicas aos programas de informação e entretenimento.

A liberdade de imprensa e o direito a informação, amparadas pela Constituição do Brasil, são dependentes de um jogo de interesses mercadológicos que privilegiam somente as elites, porque são elas que controlam majoritariamente os grandes meios de comunicação social do país. Segundo Peruzzo (2002, p. 76), “apenas dez famílias controlam a propriedade dos mais importantes meios de comunicação de abrangência nacional no Brasil."

Desse modo, o poder que esses diferentes meios de comunicação exercem sobre as pessoas, amiúde, ultrapassa os limites éticos estipulados nos manuais e códigos; o problema está no descontrole de fiscalizações e na falta de profissionalismo de alguns veículos/profissionais que preferem oferecer produtos de conteúdo grotesco e apelativo em função de uma cumplicidade junto à audiência. Na verdade, telespectadores, ouvintes ou leitores aceitam e muitos até adoram esse tipo de produto, o que é confirmado pelos institutos que aferem índices de audiência. O gosto de tal público por conteúdos apelativos revela certa permissividade nos padrões morais contemporâneos, seja por falta de opção ou instrução aceitam os valores ofertados como reais, verdadeiros e até interessantes, embora não represente o sentimento da maioria da população, haja vista algumas reações de repúdio e descontentamento com tais escolhas midiáticas.

A falta de percepção crítica sobre como funcionam os meios de comunicação social e a dificuldade de acesso a canais que possibilita ao sujeito manifestar, vigiar e intervir nas atividades exercidas pelas mídias contribui para fomentar um poder elitizado, que é contrário aos interesses de uma sociedade mais igualitária, democrática e livre.

\section{CONSIDERAÇÕES FINAIS}

A ética jamais pode ser entendida somente na teoria, mas fundamentalmente na prática da cidadania e comunicação. É uma conduta que se pauta no desejo de atrelar o saber ao fazer. Como 
práxis, a ética procura desenvolver a noção sobre o ser para estabelecer aquilo que precisa ser. Ela parte da reflexão interna e visa à prática externa, tendo como referência um comportamento socialmente responsável. Concordamos com o empresário Ben Van Schaik, ex-presidente da Daimler-Chrysler/Mercedes-Benz do Brasil, quando afirmou que "o futuro será das empresas que pensarem mais nas pessoas do que em si mesmas". (LEISINGER, 2001)

Na verdade, esta polêmica, ao que parece, encontra uma solução na qual constatamos que os meios por si só não possuem poder de definir a opinião das pessoas de forma absoluta, integrando, sim, uma rede de fatores que o fazem, mas não de forma independente e isolada. Essa limitação dos efeitos da mídia teria uma dupla causa: de um lado, a existência de uma rede de comunicações interpessoais que concorrem na produção e principalmente na difusão de informações e, de outro, os mecanismos seletivos que cada receptor coloca em prática e que condicionam a sua exposição, atenção, percepção e retenção da mensagem recebida.

Conforme vimos, a ética é um conjunto de valores morais e princípios que norteiam a conduta humana na sociedade, servindo para que haja um equilíbrio e bom funcionamento social, a fim de que ninguém saia prejudicado. Nesse sentido, a ética, embora não possa ser confundida com leis, está relacionada com o sentido de justiça social. É importante ressaltar que quando falamos em ética na comunicação encontramos situações, tais como o direito de resposta; o direito de não revelar a fonte da informação, e a responsabilidade informativa, além da privacidade e limites existentes entre a liberdade de pensamentos, de consciência e de informação.

No atual contexto, podemos afirmar, com convicção, que as alternativas para construirmos uma sociedade mais humanizada, democrática e feliz não são processos simples e isolados. Ao contrário, vivemos em sociedades cada vez mais complexas e precisamos entender o que está por trás dos fatos, consequências e ou resultados produzidos por fenômenos que abrangem muitas ideias e princípios. Razão pela qual, as transformações que a educação requer na atualidade são profundas e nos remetem para a necessidade de modificações culturais, dos processos civilizatórios, e não apenas de um ou outro setor da vida social.

Uma coisa é certa: a ética é essencial em todas as profissões que buscam bem servir os que dela dependem, pois todas as capacidades necessárias ou exigíveis para o desempenho eficaz da profissão são deveres éticos. Cabe dizermos ainda que toda a função ou profissão exercida pelo comunicador deve ser pautada na ética, pois sua atividade está intimamente ligada ao social, suas atitudes influenciam diretamente na vida das pessoas e em seu bem-estar. Esse profissional não deve ter o cumprimento da ética baseado nas regras impostas, por mais que elas existam, mas, sobretudo em respeito e valorização do ser humano, valores esses desejados, almejados e 
solicitados pelo Papa Bento XVI, na matéria divulgada no jornal "O povo", aos profissionais responsáveis pelos meios de comunicação.

Desse modo, jornalistas, publicitários, relações públicas e empresários midiáticos jamais poderão se distanciar dos valores morais nem deixar de lado o que sempre foi o centro das atenções da ética: a felicidade e a formação do caráter, pois se isso acontecer a sociedade estará a mercê de um esvaziamento.

\section{REFERÊNCIAS}

BARROS FILHO, Clóvis de. Ética na Comunicação. Da Informação ao Receptor. São Paulo: Editora Moderna, 1995.

CAMARGO, Marculino. Fundamentos de ética geral e profissional. Petrópolis: Vozes, 1999.

CHRISTOFOLETTI, Rogério. Ética no Jornalismo. São Paulo: Contexto, 2008.

FREIRE, Paulo. Pedagogia da autonomia: saberes necessários à prática educativa. 23. ed. São Paulo: Paz e Terra, 1998.

GOMES, Pedro Gilberto. Comunicação: filosofia, ética e política. São Leopoldo RS: UNISINOS, 1997.

LAROUSSE. Dicionário da Língua Portuguesa. São Paulo: Editora Nova Cultural, 2000.

LEISINGER, Klaus M. SCHMITT, Karin. Ética empresarial: responsabilidade global e gerenciamento moderno. Petrópolis, Vozes, 2001.

O POVO, O povo on-line, Críticas do papa sobre ética na comunicação. Disponível em: <http://www.opovo.com.br/opovo/opiniao/763453.html> Acesso em: 20 out 2013.

PERUZZO. Cicilia M. Krohling. Ética, liberdade de imprensa, democracia e cidadania. Revista Brasileira de Ciências da Comunicação. São Paulo, v. 25, n. 2, p. 71-87, jul/dez. 2002.

RUSSELL, Bertrand. A sociedade Humana na ética e na política. Série $1^{\text {a }}$ volume 20 . Editora Nacional, 1956.

SÁ, Antonio Lopes de. Ética Profissional. 4. ed. São Paulo: Atlas, 2001.

Antonio Lopes de. Valor Ético. (2000). Disponível em: <http://www.lopesdesa.com.br/>Acesso em: 10 de maio 2009.

WEIL, Pierre. A Nova Ética Na Política, na Empresa, na Religião, na Ciência, na Vida Privada e em todas as outras instâncias. Rio de Janeiro: Editora Rosa dos Tempos, 1994. 